\title{
Synergetic Effect of Plasmonic Gold Nanorods and MgO for Perovskite Solar Cells
}

\author{
Zhetao Xia ${ }^{1}$, Chenxi Zhang ${ }^{1}$, Zhiying Feng ${ }^{1}$, Zhixing Wu ${ }^{1}$, Zengbo Wang ${ }^{2}$, Xiaohong Chen ${ }^{1}$ \\ and Sumei Huang $1, *$ \\ 1 Engineering Research Center for Nanophotonics \& Advanced Instrument, Ministry of Education, \\ School of Physics and Electronic Science, East China Normal University, North Zhongshan Rd. 3663, \\ Shanghai 200062, China; 51184700067@stu.ecnu.edu.cn (Z.X.); zhangchenxi@tyut.edu.cn (C.Z.); \\ 52194700020@stu.ecnu.edu.cn (Z.F.); 51194700078@stu.ecnu.edu.cn (Z.W.); xhchen@phy.ecnu.edu.cn (X.C.) \\ 2 School of Electronic Engineering, Bangor University, Bangor LL57 1UT, UK; z.wang@bangor.ac.uk \\ * Correspondence: smhuang@phy.ecnu.edu.cn; Tel.: +86-21-6223-3227
}

Received: 11 August 2020; Accepted: 10 September 2020; Published: 14 September 2020

\begin{abstract}
We report new structured perovskite solar cells (PSCs) using solution-processed $\mathrm{TiO}_{2} / \mathrm{Au}$ nanorods/MgO composite electron transport layers (ETLs). The proposed method is facile, convenient, and effective. Briefly, Au nanorods (NRs) were prepared and introduced into mesoporous $\mathrm{TiO}_{2} \mathrm{ETLs}$ Then, thin $\mathrm{MgO}$ overlayers were grown on the Au NRs modified ETLs by wet spinning and pyrolysis of the magnesium salt. By simultaneous use of $\mathrm{Au} \mathrm{NRs}$ and $\mathrm{MgO}$, the power conversion efficiency of the PSC device increases from $14.7 \%$ to $17.4 \%$, displaying over $18.3 \%$ enhancement, compared with the reference device without modification. Due to longitudinal plasmon resonances (LPRs) of gold nanorods, the embedded Au NRs exhibit the ability to significantly enhance the near-field and far-field (plasmonic scattering), increase the optical path length of incident photons in the device, and as a consequence, notably improve external quantum efficiency (EQE) at wavelengths above $600 \mathrm{~nm}$ and power conversion efficiency (PCE) of PSC solar cells. Meanwhile, the thin MgO overlayer also contributes to enhanced performance by reducing charge recombination in the solar cell. Theoretical calculations were carried out to elucidate the PV performance enhancement mechanisms.
\end{abstract}

Keywords: perovskite solar cells; Au nanorods; longitudinal plasmon resonance; transverse plasmon resonance; $\mathrm{MgO}$ passivation layer; plasmon enhancement

\section{Introduction}

Perovskite solar cells (PSCs) have made great progress during the recent decade, due to their appropriate band structure, uncomplicated production process, low cost, excellent light absorption, great carrier diffusion length, and ambipolar diffusion [1-3]. Since organometal halide perovskites were first introduced by Miyasakaet al. in 2009 [4], the power conversion efficiency (PCE) of PSCs has risen rapidly from $3.8 \%$ to current certified $25.2 \%$ [5]. To date, a comparable PCE to that of traditional single crystalline or polycrystalline silicon photovoltaic (PV) devices has been realized with PSCs, indicating intense prospects of commercialization.

To promote the PCE of PSC solar cells, vigorous investigators have explored and established diversified device engineering approaches, such as interface modification, morphology optimization, defect and contact passivation, device structure design, light management, etc. [6-12]. It is well known that the organic-inorganic lead halide perovskites efficiently make use of the visible light spectrum of the solar energy from 350 to $750 \mathrm{~nm}$. However, the usage efficiency of photons with energy out of this electromagnetic wavelength region is impoverished, which restricts the PV performance of PSCs. Therefore, various tactics to promote the light absorption of perovskite semiconductor material 
over all the visible spectral regions are taken by researchers $[10,13]$. Effective light management can be accomplished by the reduction of reflection losses at the cell surface and trapping of light in the absorbing layer [14,15]. In the past decade, plasmonic nanostructures have been intensively pursued to improve the efficiency of a wide range of solar cells, including polymer solar cells, dye-sensitized solar cells, and heterojunction solar cells [16-19].

Recently, researchers have reported that the introduction of insulative metal oxide-coated spherical-shaped noble metal particles into PSC solar cells can promote PV efficiency [11,12,20-24]. The PV performance improvements could be associated with a collective effect of localized surface plasmon resonance (LSPR) promoted light absorption, decreased exciton binding energy [20], plasmonic-induced photon recycling [21], and hot-electron injection [22]. By use of the Fermi golden rule to the plasmon coupling with band electrons, microscopic calculations demonstrate that the device efficiency increase can be induced by the light absorption channel and the reduction of exciton binding energy in PSCs metalized with core-shell nanoparticles. Both absorption and electrical channels of the plasmon PV effect work for device efficiency enhancement [23,24]. To date, however, there is no direct experimental testimony that the PV performance improvement is associated with LSPR-enhanced light absorption. In addition, traditional gold and silver nanoparticles are not efficient in boosting the light absorption of widely reported lead-based perovskite semiconductors, owing to their high absorption coefficient in the wavelength region of 500-650 nm [2,25]. By comparison, perovskite semiconductors bear lower light capture in the lower frequency or longer wavelength region. The absorption coefficient considerably declines with the increase in the wavelength from 650 to $800 \mathrm{~nm}$, and the absorption almost vanishes when the wavelength is longer than $800 \mathrm{~nm}$ due to the steep absorption edge [26]. In contrast to the usually used spherical-shaped noble metal nanomaterials, the geometrically anisotropic rod-like structures are likely to present anisotropic conductivity to electron migration between the transverse and longitudinal directions [27]. The transverse resonance absorption peak of rod-like structure can promote the direct employment of the visible light. Longitudinally, it can boost the optical scattering, increase the optical path length, and promote the possibility of photon harvesting, especially for the near-infrared light (NIR) [28]. Therefore, it is expected that the LSPR effect of metal nanorods can effectively utilize photon energy chiefly through both far-field scattering and near-field improvement, thus promoting the PV performance of PSC devices [29]. The investigation of novel plasmonic nanostructures with appropriate and predesigned size and shape is demanded to make this field move forward.

In this contribution, for the first time, we utilize a novel nanostructure of an $\mathrm{Au}$ nanorod-MgO overlayer to promote the light-harvesting and PV performance of PSCs. Au NRs were synthesized and introduced onto mesoporous $\mathrm{TiO}_{2}$ films. Successively, $\mathrm{MgO}$ passivation layers were grown on the gold NR modified mesoporous $\mathrm{TiO}_{2}$. Differing from conventional metallic nanospheres, these $\mathrm{Au}$ NRs are gifted with strong absorption and scattering efficiencies in a wide wavelength region between 600 and $800 \mathrm{~nm}$. In such structure-engineered $\mathrm{TiO}_{2} / \mathrm{Au} \mathrm{NRs} / \mathrm{MgO}$ electrodes, the nanorod focuses the incident light, causing effective intensification in both near-field and scattering cross-sections, which enhance the photocurrent of PSCs. Moreover, the thin MgO overlayer also contributes to better PV performance by reducing charge recombination in the device. By embedding Au NRs/MgO in the PSC device, we observed prominent EQE enhancements at the NIR frequencies. As a result, the energy conversion efficiency of the perovskite solar cell increased from $14.7 \%$ to $17.4 \%$, demonstrating over $18.3 \%$ enhancement, compared with the reference device without modification. The PV performance enhancement mechanisms were investigated using numerical simulations. The theoretical calculations correspond well with our experimental results. 


\section{Materials and Methods}

\subsection{Materials}

All chemicals were ordered from Sigma-Aldrich (Shanghai, China) or Alfa Aesar (Shanghai, China), unless otherwise stated. They were used as received without further purification.

\subsection{Synthesis of Gold Nanorods (Au NRs)}

$\mathrm{Au}$ NRs were synthesized through a seed-mediated growth approach with slight modification, as previously reported [30]. Specifically, a $500 \mu \mathrm{L}$ portion of hydrogen tetrachloroaurate-(III) $\left(\mathrm{HAuCl}_{4} \cdot 4 \mathrm{H}_{2} \mathrm{O}\right)$ aqueous solution $(0.01 \mathrm{M})$ was mixed with $0.7289 \mathrm{~g}$ cetyltrimethylammonium bromide $(\mathrm{CTAB})$ in deionized (DI) water $(20 \mathrm{~mL})$, and then $1.2 \mathrm{~mL}$ of fresh ice-cold $\mathrm{NaBH}_{4}(0.01 \mathrm{M})$ solution was rapidly added with gentle mixing for $2 \mathrm{~min}$. The synthetic pale yellow-brown colored solution was kept at $25^{\circ} \mathrm{C}$ at least $2 \mathrm{~h}$ before the next step, and the obtained seed solution can be stable for a few days.

A $2.0 \mathrm{~mL}$ volume of $\mathrm{HAuCl}_{4}(0.01 \mathrm{M}), 0.27 \mathrm{~mL}$ of $\mathrm{AgNO}_{3}(0.01 \mathrm{M})$, and $1.4578 \mathrm{~g}$ of CTAB were mixed in $40 \mathrm{~mL}$ of DI water by gentle stirring at $25^{\circ} \mathrm{C}$. After the addition of $0.32 \mathrm{~mL}$ of freshly prepared L-Ascorbic acid solution $(0.1 \mathrm{M})$, the growth solution changed from dark yellow to colorless. Subsequently, $96 \mu \mathrm{L}$ of seed solution was added to the growth solution, and the mixed solution was left quietly at least $6 \mathrm{~h}$ at $25^{\circ} \mathrm{C}$. The Au NRs were separated and washed for several times by re-centrifugation at $4000 \mathrm{rpm}$ to remove superfluous CTAB and other possible impurities, and then dispersed in ethanol.

\subsection{Device Fabrication}

Fluorine-doped tin oxide (FTO)-coated slides (Pilkington TEC 15, Xiamen, China) were patterned by etching with $\mathrm{Zn}$ powders and $2 \mathrm{M} \mathrm{HCl}$. The etched slides were then cleaned with liquid detergent, acetone, ethyl alcohol, and DI water for $15 \mathrm{~min}$, sequentially, to remove the organic or inorganic residues, and were finally dried in a vacuum oven (Yiheng, Shanghai, China). Isopropyl titanate $(200 \mu \mathrm{L})$ and anhydrous ethanol $(5 \mathrm{~mL})$ were mixed to prepare a clear precursor sol. The formed precursor sol was spin-coated onto the primed FTO substrate at $4500 \mathrm{rpm}$ for $30 \mathrm{~s}$, followed by annealing at $500{ }^{\circ} \mathrm{C}$ to form a compact $\mathrm{TiO}_{2}$ layer $\left(\mathrm{c}-\mathrm{TiO}_{2}\right)$. Diluted $\mathrm{TiO}_{2}$ pastes were prepared by mixing $\mathrm{TiO}_{2}$ paste (Dyesol 18NR-T, Queanbeyan, Australia) and anhydrous ethanol (weight ratio: 1:3.5), and the resulting pastes were stirred overnight. The mesoporous $\mathrm{TiO}_{2}\left(\mathrm{p}-\mathrm{TiO}_{2}\right)$ layer was formed on the $\mathrm{c}-\mathrm{TiO}_{2}$ layer by spin-coating diluted $\mathrm{TiO}_{2}$ pastes at $2000 \mathrm{rpm}$ for $45 \mathrm{~s}$. The layer was then sintered at $500{ }^{\circ} \mathrm{C}$ for $30 \mathrm{~min}$ in air. After the samples cooled down to the room temperature, $75 \mu \mathrm{L}$ of $\mathrm{Au}$ NRs solution $\left(0.20 \mathrm{mg} \mathrm{mL}^{-1}\right)$ was first spin-coated onto the $\mathrm{p}-\mathrm{TiO}_{2}$ film's surface, followed by heating at $100{ }^{\circ} \mathrm{C}$ for $30 \mathrm{~min}$ on a hotplate in air. The $\mathrm{MgO}$ insulative film was formed on the Au NRs coated $\mathrm{p}-\mathrm{TiO}_{2}$ layer by spin-coating $\mathrm{Mg}\left(\mathrm{CH}_{3} \mathrm{COO}\right)_{2}$ dissolved in DI water $(0.045 \mathrm{M})$ at $4000 \mathrm{rpm}$ for $30 \mathrm{~s}$, then heated at $400{ }^{\circ} \mathrm{C}$ for $1 \mathrm{~h}$. The perovskite $\mathrm{MAPbI}_{3}\left(\mathrm{MA}=\mathrm{CH}_{3} \mathrm{NH}_{3}\right)$ layer was grown by a spin-coating process using a $\gamma$-butyrolactone (GBL)/dimethylsulphoxide (DMSO) solution of $\mathrm{CH}_{3} \mathrm{NH}_{3} \mathrm{I}$ and $\mathrm{PbI}_{2}[6,7]$. The perovskite precursor solution was prepared by mixing $\mathrm{CH}_{3} \mathrm{NH}_{3} \mathrm{I}(0.1975 \mathrm{~g})$ powders and $\mathrm{PbI}_{2}(0.5785 \mathrm{~g})$ in GBL $(700 \mu \mathrm{L})$ and DMSO $(300 \mu \mathrm{L})$ at room temperature overnight. The formation of the absorber precursor layers involved spin-coating the perovskite precursor solution at 2000 and $4000 \mathrm{rpm}$ for 20 and $50 \mathrm{~s}$, respectively. At the second spin-coating step, anhydrous chlorobenzene (CB) antisolvent was dripped onto the center of the sample. The perovskite precursor coated sample was heated on a hot plate at $100{ }^{\circ} \mathrm{C}$ for $30 \mathrm{~min}$. The hole transport layer (HTL) was deposited by spin-coating a spiro-OMeTAD solution with $0.0723 \mathrm{~g}$ spiro-MeOTAD, $28.8 \mu \mathrm{L}$ of 4 -tert-butylpyridine, and $17.5 \mu \mathrm{L}$ of Li TFSI (520 mg Li TFSI in $1 \mathrm{~mL}$ of acetonitrile) dissolved in $1 \mathrm{~mL}$ of CB at $4000 \mathrm{rpm}$ for $30 \mathrm{~s}$ [31]. Finally, a $100 \mathrm{~nm}$ thick Ag electrode with an active area of $0.1 \mathrm{~cm}^{2}$ was formed on the Spiro-OMeTAD-coated film by thermal evaporation. 


\subsection{Characterization}

The surface morphologies of $\mathrm{Au}$ NRs and $\mathrm{Au}$ NRs modified $\mathrm{p}-\mathrm{TiO}_{2}$ films were recorded by a high-resolution field emission scanning electron microscope (FESEM, Hitachi S4800, Tokyo, Japan). The absorption spectra of $\mathrm{p}-\mathrm{TiO}_{2}$-based perovskite absorbers with various modifications were examined and characterized by means of ultraviolet-visible light (UV-vis) spectrometer (Hitachi, U-3010, Tokyo, Japan). Photoluminescence (PL) spectra were measured using a HORIBA JobinYvon fluoromax-4 fluorescence spectrophotometer (Edison, NJ, USA) with an excitation wavelength of $508 \mathrm{~nm}$ at room temperature. The external quantum efficiency (EQE) spectra were recorded with the Optical Power Meter (Newport 2936-R, Irvine, CA, USA). The $J-V$ characteristics were measured with the source meter controlled by a computer (Keithley model 2440, Solon, OH, USA) under simulated solar illumination (AM1.5G/100 mW/cm², Newport solar simulator, Irvine, CA, USA) in the air. The electrochemical workstation (PG30.FRA2 Autolab, EcoChemie, Utrecht, The Netherlands) was used to measure electrochemical impedance spectroscopy (EIS) curves of the PSCs.

\section{Results and Discussion}

A series of devices with basic configuration (glass/FTO/c-TiO $/$ p- $\mathrm{TiO}_{2} / \mathrm{CH}_{3} \mathrm{NH}_{3} \mathrm{PbI}_{3} /$ spiro-OMeTAD/ $\mathrm{Ag}$ ) were fabricated and modified with and without $\mathrm{Au} \mathrm{NRs} \mathrm{and/or} \mathrm{MgO.} \mathrm{The} \mathrm{current} \mathrm{density} \mathrm{versus}$ voltage $(J-V)$ curves from the four types of fabricated PSC devices are shown in Figure 1a. Table 1 lists the summary of PV performance parameters of PSCs, including open-circuit voltage $\left(V_{\mathrm{OC}}\right)$, short-circuit current density $\left(J_{S C}\right)$, fill factor $(F F)$, and PCE. Figure 1b,d shows FESEM images of as-deposited gold NRs and the top surface morphology of the porous $\mathrm{TiO}_{2}$ layer modified with $\mathrm{Au}$ NRs, respectively. From both figures, the average size of Au NRs is about $12 \mathrm{~nm}$ in diameter and $40 \mathrm{~nm}$ in length, the Au nanorods have an aspect ratio of about 3.3, and Au NRs are distributed on the top surface of the $\mathrm{p}-\mathrm{TiO}_{2}$ as shown in Figure 1d. The Au nanorods show a transverse SPR band at $519 \mathrm{~nm}$ and a longitudinal SPR band at $665 \mathrm{~nm}$, while Au spheres with a diameter of $20 \mathrm{~nm}$ display an SPR peak at $520 \mathrm{~nm}$, as shown in Figure 1c.

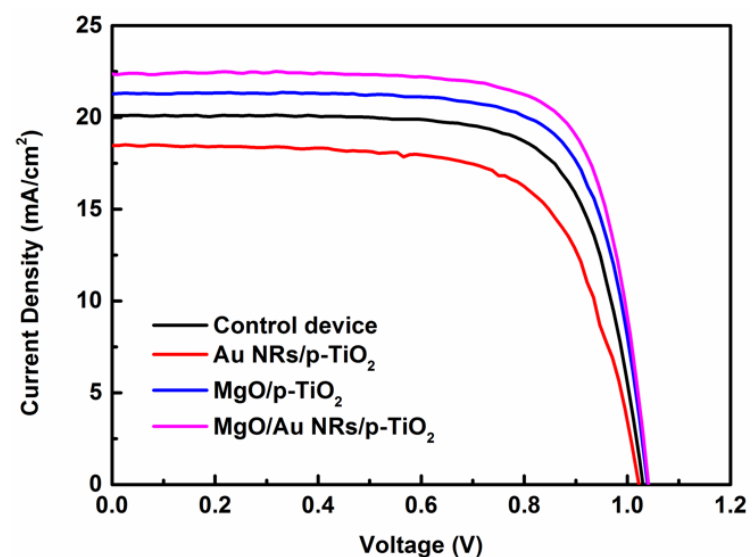

(a)

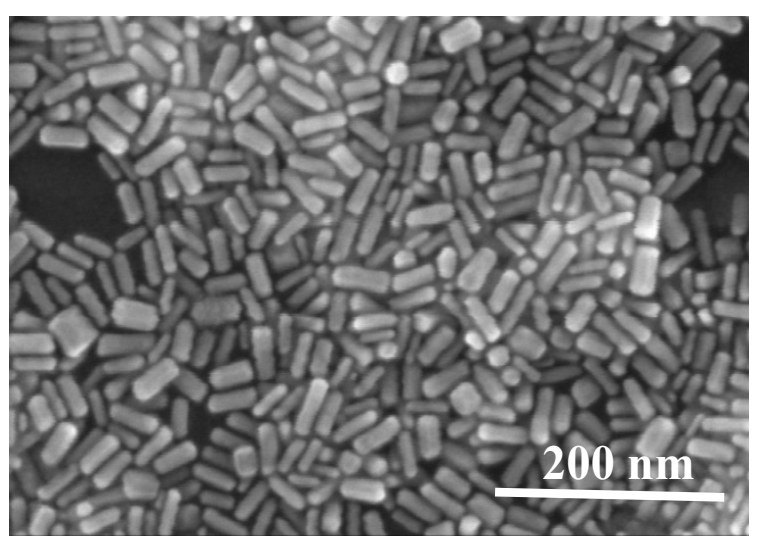

(b)

Figure 1. Cont. 


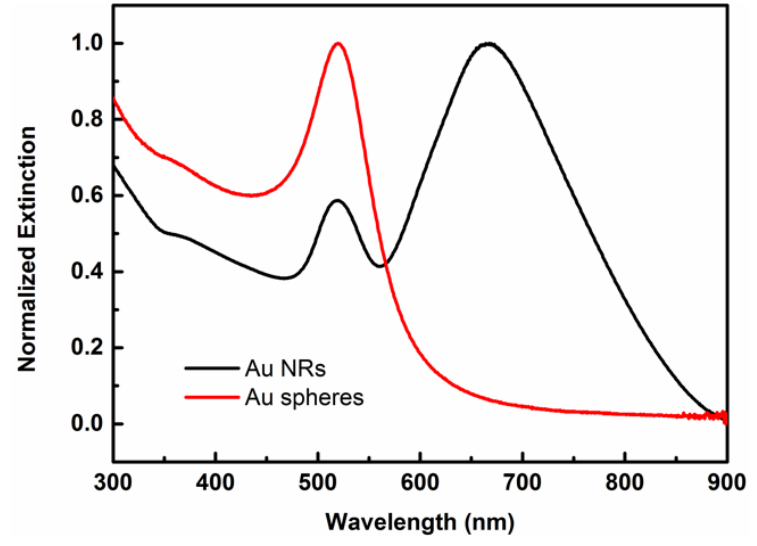

(c)

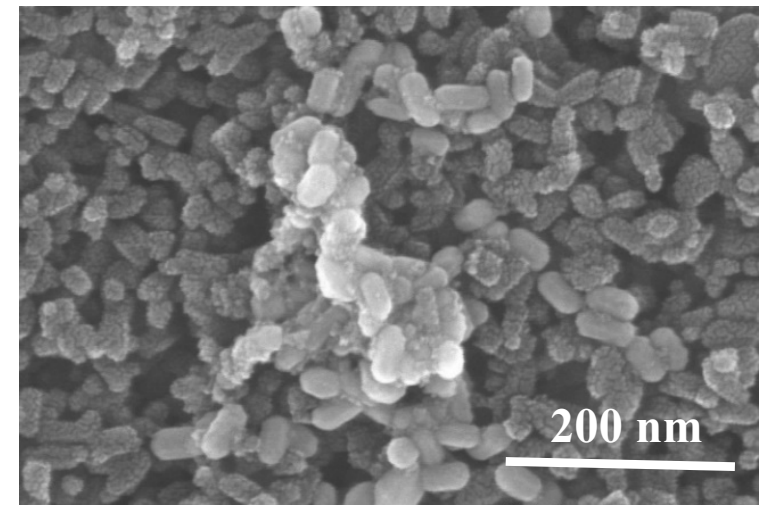

(d)

Figure 1. (a) $J-V$ curves of perovskite solar cell (PSC) devices based on porous $\mathrm{TiO}_{2}$ without and with $\mathrm{Au}$ NRs and $\mathrm{MgO}$ coating. (b) FESEM image of as-deposited gold NRs. (c) Absorbance spectrum of $\mathrm{Au}$ NRs and Au spheres (about $20 \mathrm{~nm}$ in diameter) suspensions. (d) FESEM image of the top surface morphology of the porous $\mathrm{TiO}_{2}$ layer modified with $\mathrm{Au}$ NRs.

Table 1. Photovoltaic parameters of the PSCs based on $\mathrm{m}-\mathrm{TiO}_{2}$ with and without Au nanorods (NRs) and/or $\mathrm{MgO}$.

\begin{tabular}{ccccc}
\hline Parameters & $V_{\text {OC }}(\mathbf{V})$ & $J_{S C}\left(\mathbf{m A} / \mathbf{c m}^{2}\right)$ & FF & PCE (\%) \\
\hline Control & 1.02 & 20.10 & 0.72 & 14.7 \\
With pure Au NRs & 1.01 & 18.51 & 0.68 & 12.7 \\
With pure MgO & 1.04 & 21.30 & 0.74 & 16.4 \\
With Au NRs/MgO & 1.04 & 22.35 & 0.75 & 17.4 \\
\hline
\end{tabular}

As can be seen from Table 1, the reference device without $\mathrm{Au}$ NRs or MgO coatings shows a PCE value of $14.7 \%$ with a $V_{\mathrm{OC}}$ of $1.02 \mathrm{~V}, J_{\mathrm{SC}}$ of $20.10 \mathrm{~mA} / \mathrm{cm}^{2}$, and $\mathrm{FF}$ of 0.72 . By incorporating bare $\mathrm{Au}$ NRs between the $\mathrm{p}-\mathrm{TiO}_{2}$ and perovskite layers, the performance of the device degraded notably and displayed a PCE value of $12.7 \%$ with a $V_{\mathrm{OC}}$ of $1.01 \mathrm{~V}, J_{\mathrm{SC}}$ of $18.51 \mathrm{~mA} / \mathrm{cm}^{2}$, and FF of 0.68 . Both short-circuit current density and fill factor values decreased prominently, after the addition of $\mathrm{Au}$ NRs alone. Compared to the case of the control device, the device modified by pure MgO exhibited a PCE of $16.4 \%$, the value of $V_{\mathrm{OC}}, J_{\mathrm{SC}}$, and FF increased a little. The champion cell performance was obtained for the cell modified with both $\mathrm{Au} \mathrm{NRs}$ and $\mathrm{MgO}$. This cell manifested an open-circuit voltage of $1.04 \mathrm{~V}$, a short-circuit current density of $22.35 \mathrm{~mA} / \mathrm{cm}^{2}$, and a fill factor of 0.75 , resulting in the highest PCE of $17.4 \%$. Compared with the reference device, the PCE enhancement for the device incorporating both $\mathrm{Au} \mathrm{NRs}$ and $\mathrm{MgO}$ mainly comes from the greatly improved short-circuit photocurrent $J_{\mathrm{SC}}\left(20.10\right.$ to $\left.22.35 \mathrm{~mA} / \mathrm{cm}^{2}\right)$ and the fill factor $(0.72$ to 0.75$)$, while the open-circuit voltage $V_{\mathrm{OC}}$ is only slightly changed.

It can be seen that the main performance difference between these four kinds of devices is the short-circuit photocurrent and the fill factor from Table 1. The $J_{S C}$ and the fill factor of the PSC device incorporated only Au NPs degraded a lot, which can be associated with two factors. The bared gold NRs can play as charge carrier recombination or trapping sites for photon-induced carriers due to the lower conduction energy level of the $\mathrm{Au}$ than that of the $\mathrm{TiO}_{2}[32,33]$. On the other hand, the $\mathrm{Au}$ NRs are possibly corroded by the halides during the thermal annealing treatment of the perovskite precursor films, leading to the metal migration or diffusion into the perovskite material, and thus, causing destructive and irreversible alterations to the perovskite active layers and consequently, seriously impacting the solar cell performance [33,34]. From Table 1, the PV performance of the device with pure $\mathrm{MgO}$ modification showed enhanced $V_{\mathrm{OC}}$ values, especially $J_{\mathrm{SC}}$ and FF values compared with the reference device. The increase in the $V_{\text {oc }}$ parameter can be chiefly ascribed to the much higher 
conduction band energy level of $\mathrm{MgO}$ than that of $\mathrm{TiO}_{2}$. The condition could induce a positive shift of the $\mathrm{TiO}_{2}$ conduction band towards that of $\mathrm{MgO}$ and achieve a higher quasi-Fermi level under solar light irradiation and a higher open-circuit voltage [35]. Besides, the ultrathin MgO overlayer could play as a tunneling barrier that obstructs the recombination receded from $\mathrm{TiO}_{2}$ to the hole transport material in the solar cell, thus, high $J_{\mathrm{sc}}$ and FF parameters were obtained. Obstruction of charge carrier recombination is also testified by the following electrochemical impedance spectroscopy (EIS) measurement data. As a result, by simultaneously applying Au NRs and MgO coating in the PSC, the solar cell performance was further improved, and the PSC cell using both Au NRs and MgO overlayer is better than the other three kinds of PSC devices.

As a promising wide bandgap semiconductor and good tunneling and spintronics material, $\mathrm{MgO}$ has been widely reported to change the surface state of metal oxide electrodes and reduce interfacial carrier recombination in solar cells [35-37]. In our work, in addition to the roles reported in the previous literature, $\mathrm{MgO}$ coating also worked as an insulative shell to screen gold nanorods, keeping gold nanorods intact and maintain their structural and thermal stability during the annealing treatment of the perovskite precursor films [33]. The wide bandgap MgO overlayer prevented the gold NRs on the porous $\mathrm{TiO}_{2}$ from etching or metal migrating during fabricating perovskite active films. The metal ion diffusion into the absorber layer will have a detrimental effect on device performance and cause leakage current. The $\mathrm{MgO}$ coating also blocked the direct contact between gold and the perovskite semiconductor, or the hole conductor material in the PSC, suppressing undesired electron-hole recombination routes within the solar cell. From Table 1, compared with the PSC cell with pure $\mathrm{MgO}$ modification, the PSC cell containing both $\mathrm{Au}$ NRs and $\mathrm{MgO}$ coating displayed analogous $V_{\mathrm{OC}}$ and FF values, but a remarkably higher short-circuit current. The increase in photocurrent in the latter device compared to the former device suggested that localized surface plasmon resonance (SPR) and electrical effects of Au NRs enhance the PV response of the solar cells [11,38-40].

In order to explore the optical and electrical effects of gold NRs on the PV performance of PSC devices, optical absorption and steady-state PL spectra of the $\mathrm{TiO}_{2}$ electron transport layer (ETL) and absorber samples were measured. Figure $2 \mathrm{a}$ shows the UV-vis spectra of $\mathrm{FTO} / \mathrm{c}-\mathrm{TiO}_{2} / \mathrm{p}-\mathrm{TiO}_{2}$ samples without or with $\mathrm{Au} \mathrm{NRs} \mathrm{and} \mathrm{MgO} \mathrm{modification.} \mathrm{All} \mathrm{the} \mathrm{ETL} \mathrm{specimens} \mathrm{exhibit} \mathrm{an} \mathrm{analogous} \mathrm{light}$ absorption, illustrating that the introduction of $\mathrm{Au} \mathrm{NRs}$ or $\mathrm{MgO}$ into the porous $\mathrm{TiO}_{2}$ ETL had no obvious negative effect on the transparency of the $\mathrm{TiO}_{2}$ ETL. Figure $2 \mathrm{~b}$ exhibits the UV-vis spectra of perovskite absorber samples without or with $\mathrm{Au} \mathrm{NRs} \mathrm{and} \mathrm{MgO}$ modification. No obvious change was observed in the absorption spectra of the four types of absorber specimen, even in the region of specific absorption wavelengths linked with gold NRs shown in Figure 1c, which is in good agreement with the previously reported results $[20,21]$. The consequence can be understood by considering the extremely high absorption coefficient of the $\mathrm{Pb}$ based perovskite and the small amounts of the added gold NRs or MgO.

On the other hand, the charge carriers produced in the perovskite absorber of the plasmonic PSC are likely to transport and collect more efficiently. Steady-state PL characterizations are effective in exploring the carrier transporting properties and recombination of light-excited electrons and holes of the solar cells. PL spectra of perovskite absorbers without or with Au NRs and $\mathrm{MgO}$ modification are shown in Figure 2c. All absorber samples display an emissive peak at around $761 \mathrm{~nm}$. The PL peak position almost remained constant for the four absorbers, however, their PL intensities and quenching changed a lot. Particularly, the absorber specimen with bare Au NRs displayed the strongest fluorescence signal, and the corresponding perovskite solar cell prospectively showed a higher recombination rate of carriers than the devices based on the other absorber specimens. Nevertheless, compared to the control sample, a significantly enhanced PL quenching was detected for both kinds of absorber samples with $\mathrm{MgO}$ overlayer, testifying that electron extraction from perovskite to $\mathrm{TiO}_{2}$ ETLs with $\mathrm{MgO}$ modification was more efficient than the case to the pristine $\mathrm{TiO}_{2}$. Compared with that of the reference absorber without any modification, the fluorescence intensity becomes less and less intense from the absorber with pure $\mathrm{MgO}$ to the one containing gold nanorods and $\mathrm{MgO}$. 
The much lower PL intensity for the latter sample demonstrates that simultaneously incorporating $\mathrm{Au}$ NPs and MgO onto porous ETLs plays a dominant role in promoting the charge transfer and blocking the recombination between photogenerated electrons and holes. The perovskite layer grown on the $\mathrm{MgO} / \mathrm{Au} \mathrm{NRs} / \mathrm{ETL} / \mathrm{FTO}$ substrate displays the most intense PL quenching behavior. The most strongly quenching characteristic suggests the speediest charge transfer, the most efficient electron extraction and the least charge accumulation, and thus, the highest $J_{\mathrm{SC}}$ value and the best photovoltaic performance [41]. This result is consistent with the PV performance parameter values analyzed in the $J-V$ curves of the fabricated PSC devices.
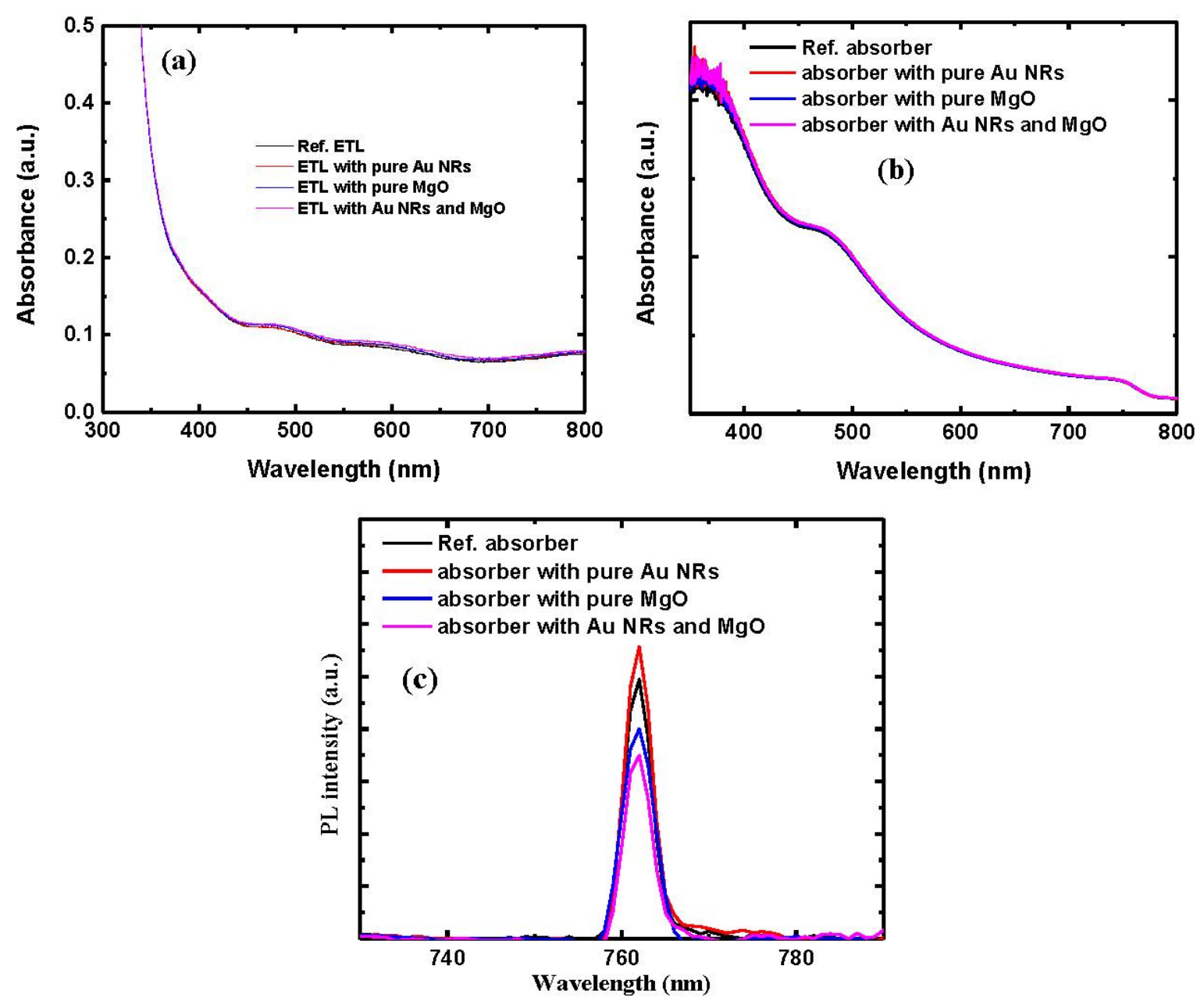

Figure 2. UV-vis absorption of (a) $\mathrm{p}-\mathrm{TiO}_{2}$ electron transport layers (ETLs) and (b) perovskite absorbers formed on porous $\mathrm{TiO}_{2}$ without and with $\mathrm{Au}$ NRs and $\mathrm{MgO}$ coating. (c) Steady-state photoluminescence (PL) spectra of perovskite absorbers without and with $\mathrm{Au}$ NRs and $\mathrm{MgO}$ coating.

EIS characterizations were also performed to study the interface charge transport and recombination in PSC devices. Figure 3 displays the Nyquist plots of the PSCs based on porous $\mathrm{TiO}_{2}$ without and with $\mathrm{Au}$ NRs or $\mathrm{MgO}$ modification. EIS measurements were carried out at a bias voltage of $0.9 \mathrm{~V}$ and in the dark. The whole perovskite solar cell can be regarded as a leaking capacitor [42]. The dimension of the semicircle in the Nyquist plot typically symbolizes the magnitude of the recombination resistance at the interface of the ETL/perovskite layer and ETL/hole transport layer. As can be seen from Figure 3, the PSC cell with bare gold nanorods shows the smallest semicircle, indicating the lowest recombination resistance. The control device displays the second-lowest recombination resistance. With the pure $\mathrm{MgO}$ modification, the diameter of the semicircle dramatically increases, indicating extremely higher recombination resistance in the device 
with pure $\mathrm{MgO}$ modification than that of the control cell and the PSC with bare Au NRs. The PSC device containing both $\mathrm{Au} \mathrm{NRs} \mathrm{and} \mathrm{MgO}$ exhibits the second-largest recombination resistance. Its recombination resistance is a little smaller than that of the PSC with bare $\mathrm{MgO}$. The increase in recombination resistance after using $\mathrm{TiO}_{2} / \mathrm{Au} \mathrm{NRs} / \mathrm{MgO}$ or $\mathrm{TiO}_{2} / \mathrm{MgO}$ composite ETLs caused a significant decrease in current loss via interfacial carrier recombination, and thus, promoted the $J_{\text {SC }}$ and the FF parameters for the corresponding PSCs as shown in Table 1.

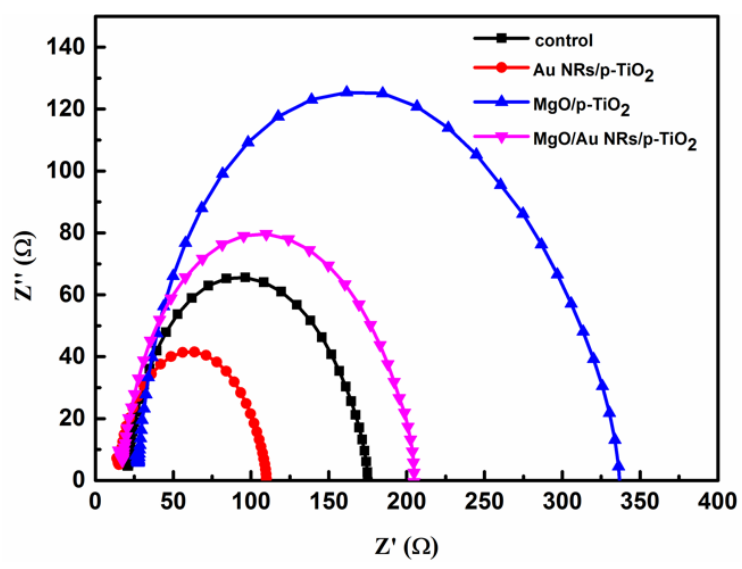

Figure 3. Nyquist plots of PSCs based on $\mathrm{p}-\mathrm{TiO}_{2}$ without and with $\mathrm{Au} \mathrm{NRs}$ and $\mathrm{MgO}$ overlayer under dark conditions at a $0.9 \mathrm{~V}$ applied bias.

EQE spectra were characterized to further investigate the photoelectric conversion capacity in the modified PSCs. The EQE can be factorized into three components enabling the origin of photocurrent loss to be examined. The element is related to the efficiency of photon harvesting by the perovskite absorber, charge injection from the excited absorber to the $\mathrm{TiO}_{2} \mathrm{ETL}$, and charge collection from the $\mathrm{TiO}_{2}$ electrode to the external circuit [43]. Thus, it is more appropriate than $J-V$ measurements for probing optical and electrical responses of PSCs. The EQE spectra of PSCs modified with and without $\mathrm{Au} \mathrm{NRs}$ and/or $\mathrm{MgO}$ are shown in Figure 4a. From the figure, the generation of photocurrent begins at $\sim 800 \mathrm{~nm}$, corresponding with the bandgap of perovskite $\mathrm{CH}_{3} \mathrm{NH}_{3} \mathrm{PbI}_{3}$. In order to examine the positive contribution of gold NRs/or magnesium oxide to the photocurrent, relative EQE variations are exhibited in Figure $4 \mathrm{~b}$ for different wavelengths. For an incident photon with a wavelength $(\lambda)$, when the relative EQE enhancement is positive, the presence of the modification improved the efficiency of the device, compared to the unmodified reference device. Negative EQE variation values mean that fewer photons were absorbed or fewer charge carriers were separated and collected by the modified PSC device. It is found that the relative EQE variation for the PSC using bare Au NRs is negative over the wavelength region from 310 to $790 \mathrm{~nm}$. In this case, the presence of bare NRs is actually deleterious to the performance of the PSC device, yielding PV cells with lower power generation than the references in the spectral range. The negative performance observed for bare Au NRs has been attributed to the reasons that the bared gold NRs can work as charge carrier recombination or trapping sites for photon generated carriers and cause destructive alterations to perovskite absorbers. The obtained EQE result for the PSC using bare Au NRs corresponds well with the decrease in the JSC data given in Table 1. EQE of the PSC with pure MgO modification was clearly improved in the wavelength region from about 400 to $600 \mathrm{~nm}$ when compared with that of the reference device. In contrast, for the PSC cell containing both $\mathrm{Au}$ NRs and MgO overlayer, the relative EQE variation curve presents positive values almost in the whole spectral range from 310 to $750 \mathrm{~nm}$. The EQE enhancements are dominant at long wavelengths, significantly displaying two positive maxima at $620 \mathrm{~nm}$ and $709 \mathrm{~nm}$, respectively. The characteristic EQE enhancement profile closely matches the Au NR extinction spectrum in Figure 1c. The positions of the maxima in long wavelengths could be associated with the longitudinal SPR bands of the colloid Au NRs immobilized on Au- and MgO-modified PSC devices. 
The positive EQE enhancement values could be partly attributed to the favorite radiation scattering into the PSC absorber mediated by the local SPR [18]. In the case of simultaneous inclusion of Au $\mathrm{NRs}$ and $\mathrm{MgO}$ coating, the incident radiation and the scattering light from colloidal Au NRs lead to constructive interference of the light waves combined at the interface of the perovskite absorber and $\mathrm{TiO}_{2}$ ETL. Additionally, the EQE enhancement can be also ascribed to the hole blocking effect of $\mathrm{MgO}$, which reduced the charge recombination in the modified device. Although multipolar scattering, such as quadrupolar contributions, can be very efficient [44], their effect at shorter wavelengths is very complicated in consideration of the mechanisms of interband transition. From Figure 4a,b, the trend in EQE enhancement for differently structured PSC devices agrees well with ours with that from $J-V$ measurement and analysis shown in Figure 1a and Table 1.

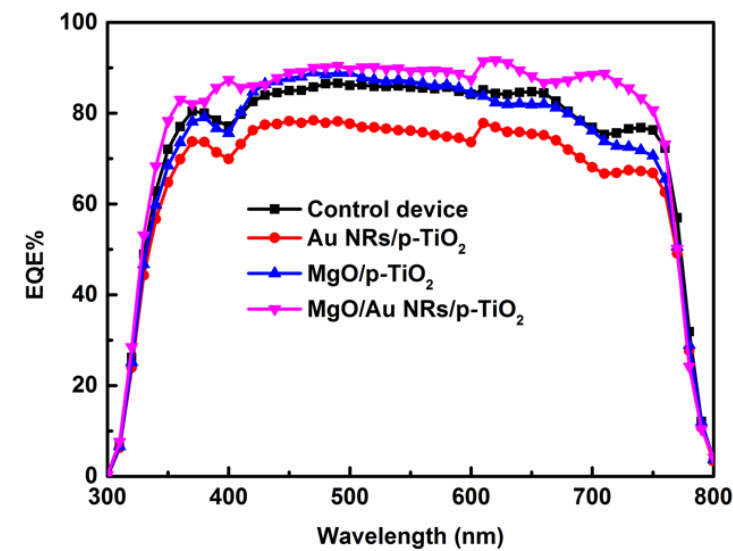

(a)

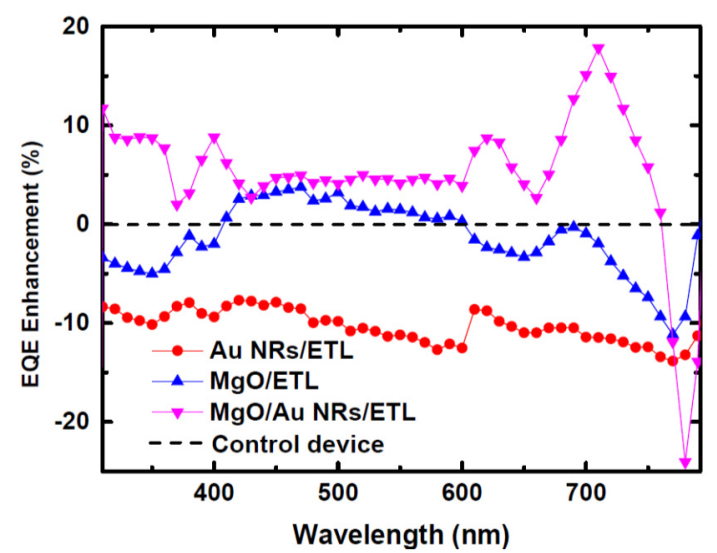

(b)

Figure 4. (a) External quantum efficiency (EQE) curves of the control (reference) device and the PSCs with $\mathrm{Au}$ NRs or MgO overlayer. (b) EQE enhancements of PSCs with Au NRs and MgO overlayer: $\mathrm{EQE}$ enhancement: $\triangle \mathrm{EQE} / \mathrm{EQE}_{\mathrm{ref}}(\triangle \mathrm{EQE}$, the difference between $\mathrm{EQE}$ values of the modified and the reference devices).

To better understand the optical effect of Au NRs on the PV performance, Finite-difference time-domain (FDTD) numerical simulations were performed to simulate the electromagnetic field within the perovskite layer containing $\mathrm{Au}$ NRs. The finite integral technique (CST Microwave Studio) was applied for the calculations $[12,33,45]$. The optical properties (refractive index, $n$, and extinction coefficient, $k$ ) of the related materials are obtained from previous publications $[25,46,47]$. FDTD numerical simulations were performed for an Au naorod $(40 \mathrm{~nm}$ in length and $11.6 \mathrm{~nm}$ in diameter) embedded between $\mathrm{TiO}_{2}$ and perovskite layers. The Au nanorod is along the $y$-direction. The incident light is a plane wave propagating at the normal incidence along the negative $z$-direction, and the polarization direction is shown in the bottom-right corner of Figure 5. The electric-field $|\mathrm{E}|$ enhancement factor distributions around the $\mathrm{Au} \mathrm{NR}$ embedded between $\mathrm{TiO}_{2}$ and perovskite layers at different wavelengths are exhibited in the figure. The enhancement factor is determined as the proportion between the electric field within the $\mathrm{TiO}_{2}$ or perovskite layers with and without the plasmonic NRs. As can be seen from Figure 5, the near-field enhancement factor around Au NR is noticeable and changes with the wavelength of the incident light. The most prominent augmentation typically occurs at the edge of the Au nanorod. The $|\mathrm{E}|$ enhancement factor of the local field is extremely high and the strength dimension is most considerably large at $620 \mathrm{~nm}$. The near-field enhancement can be a result of coupling between individual plasmonic Au NRs and the interaction between Au NR and $\mathrm{TiO}_{2} / \mathrm{CH}_{3} \mathrm{NH}_{3} \mathrm{PbI}_{3}$ in close proximity [48]. When metal and semiconductor nanomaterials are very adjacent to each other, higher-order interactions and even energy transfer may occur [49]. 


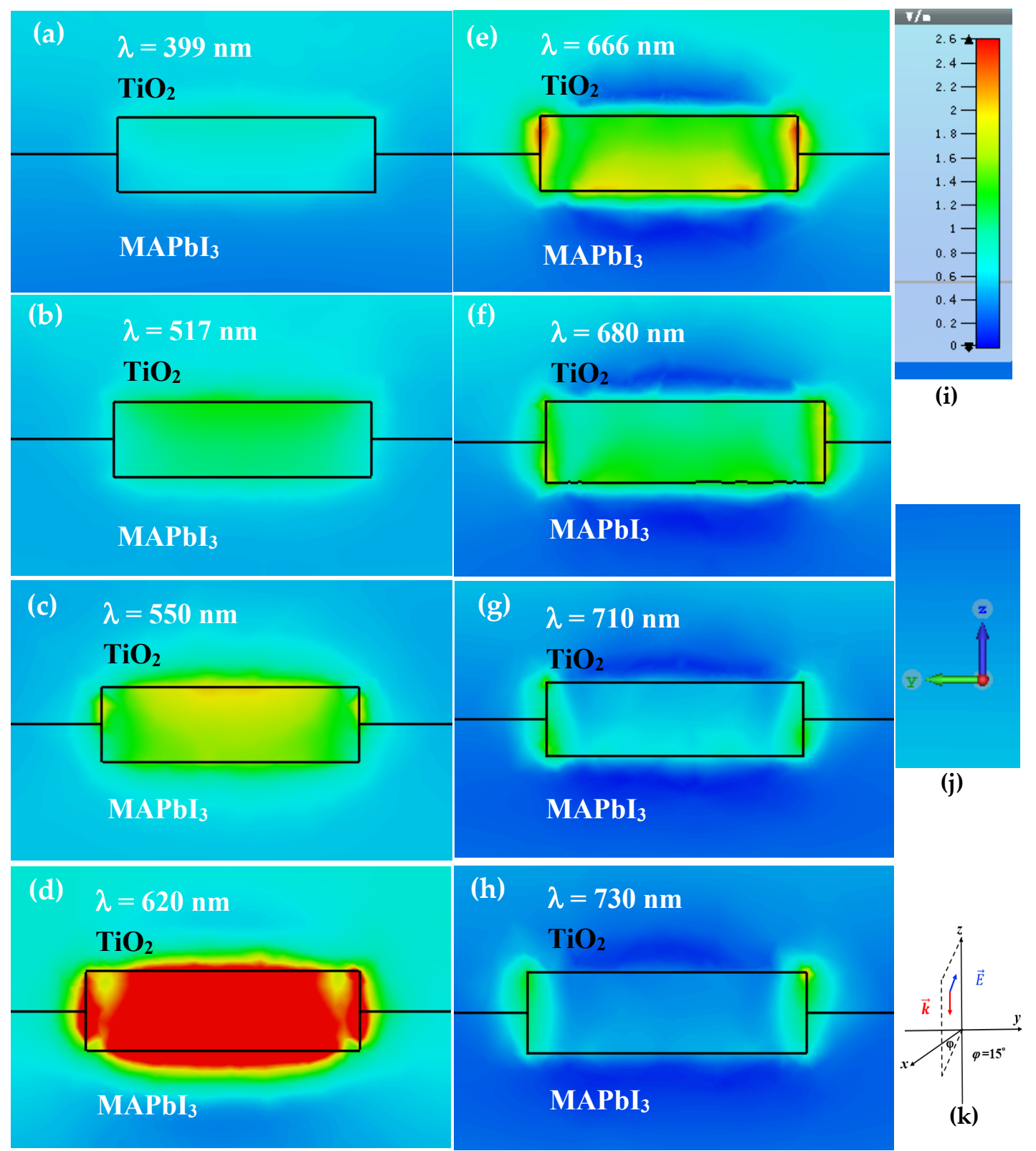

Figure 5. (a-h) Simulated field $|E|$ enhancement factor distribution around Au NR (40 nm in length and $11.6 \mathrm{~nm}$ in diameter) at different wavelengths, (i) color scale and (j) $y z$ plane. The local field-enhancement factor distributions on $y z$ planes at $x=0 \mathrm{~nm}$. (k) Incident light beam propagation is along $-z$, and the light polarized direction.

Precious metal NRs are exceptionally appealing for their high absorption and scattering efficiencies in the NIR frequencies. The corresponding longitudinal plasmon resonances (LPRs) are sensitive to the polarization of the incident excitation. Figure $6 \mathrm{a}, \mathrm{b}$ shows the calculated absorption and scattering cross-sections of an Au naorod ( $40 \mathrm{~nm}$ in length and $11.6 \mathrm{~nm}$ in diameter) and an Au sphere (20.06 nm in diameter) with the same volume as the gold nanorod. The polarization direction of the incident plane wave is the same as shown in Figure 5. The nanoorod is along the y-direction. From the simulation, gold nanorods support tremendously higher absorption and scattering cross-sections than $\mathrm{Au}$ spheres with the same volume as the Au NRs at NIR wavelengths $(600-800 \mathrm{~nm})$. Additionally, for the $\mathrm{Au} \mathrm{NR}$, the absorption cross-section value is higher than the scattering cross-section value at a fixed wavelength. The results are in good agreement with the previous work [50,51]. The insert in Figure $6 \mathrm{~b}$ shows an angular scattering diagram for the Au nanorod illuminated by a linear polarized 
plane wave with a wavelength of $620 \mathrm{~nm}$ in free space. Furthermore, the simulated transverse and longitudinal plasmon resonances (LPSs) of the Au NRs are $508 \mathrm{~nm}$ and $665 \mathrm{~nm}$, respectively, from the absorption cross-section curve shown in Figure 6a. The scattering cross-section curve also displays an LPS at $665 \mathrm{~nm}$, as shown in Figure 6b. The calculated transverse plasmon resonance and LPS results are very consistent with those from the measured absorbance spectra of Au NRs and spheres shown in Figure 1c.
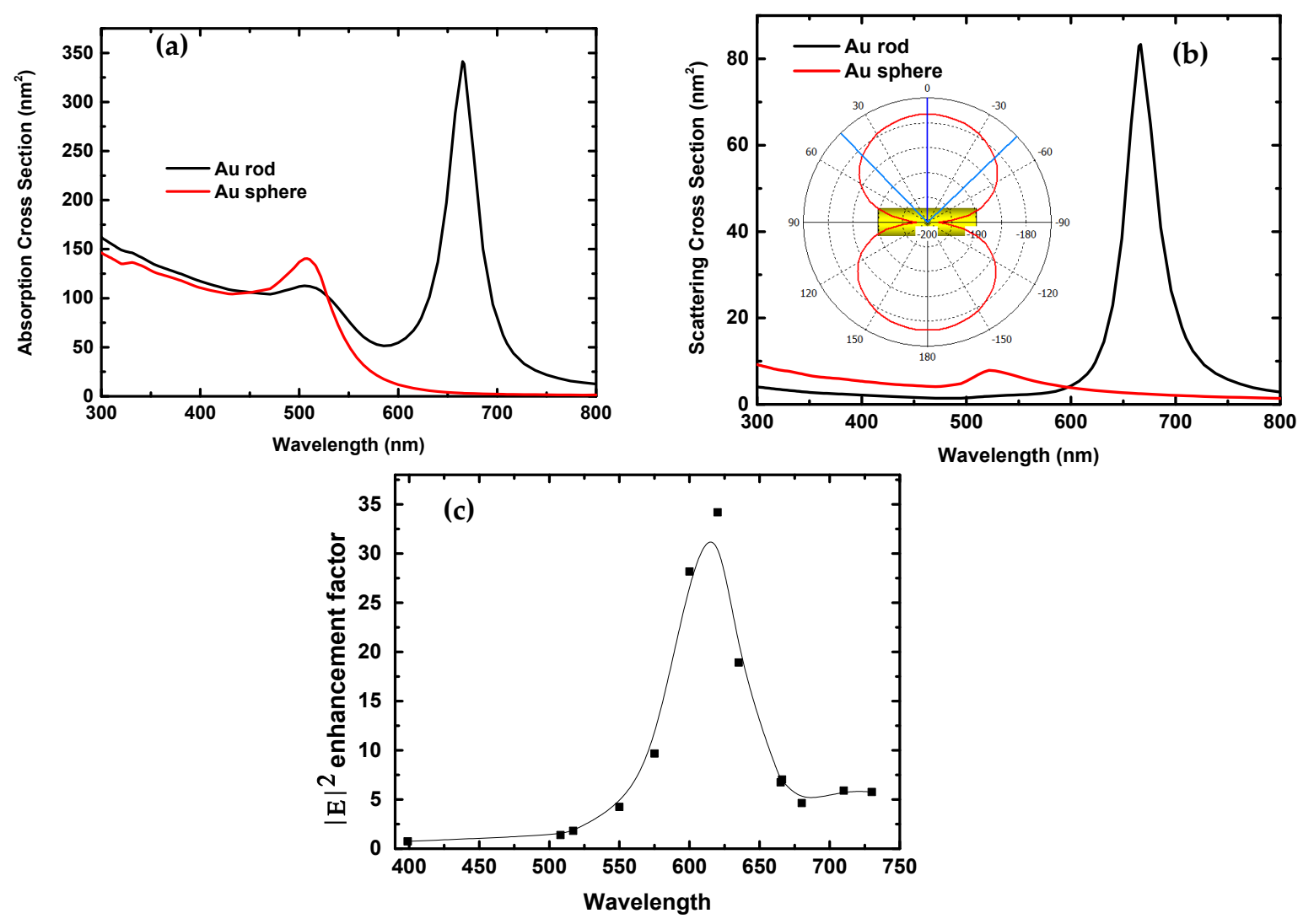

Figure 6. Calculated absorption (a) and scattering (b) cross-sections of an Au NR (40 nm in length and $11.6 \mathrm{~nm}$ in diameter) and sphere (20.06 $\mathrm{nm}$ in diameter) by a linear polarized plane wave in free space. The insert is the scattering diagram for the Au NR at a wavelength of $620 \mathrm{~nm}$. (c) Maximal field intensity $|E|^{2}$ enhancement factor around the Au NR at different wavelengths.

Figure $6 \mathrm{c}$ shows the dependence of the maximal electric-field intensity $|\mathrm{E}|^{2}$ enhancement factor around $\mathrm{Au} \mathrm{NR}$ embedded between $\mathrm{TiO}_{2}$ and $\mathrm{MAPbI}_{3}$ films on the wavelength of the incident light beam. From the figure, the maximal $|E|^{2}$ enhancement factor increases with the increase in the wavelength from 400 , reaches a maximum at $620 \mathrm{~nm}$, and then drops down with the further increase in the wavelength from $620 \mathrm{~nm}$. The electric field's intensity in the perovskite layer containing $\mathrm{Au}$ NRs can be increased by close to 35 times than the incident light field at the wavelength of $620 \mathrm{~nm}$, where both the maximal absolute EQE value and one EQE enhancement peak took place as shown in Figure $4 \mathrm{a}, \mathrm{b}$, respectively. This coincidence between the near-field enhancement peak and the position of the maximal absolute EQE or the positive peak in EQE variations undoubtedly support that the enhanced local electric field boosted the generation rate of electron-hole pairs and thereby upgraded the PV performance of PSC solar cells followed by increases in photocurrent and power conversion efficiency [21]. In our study, the nanorods are randomly distributed in the perovskite absorber, which induces complexity in the effecting of LSPRs, but still will evidently enhance the optical response and the EQE values at plasma resonances. 
We have mainly discussed the optical effect of Au NRs on the PV performance in the above simulation sections. Actually, plasmons can contribute to modifying not only light absorption but also local electricity inside a PSC cell metalized with core-shell nanoparticle [12,20-24]. Both optical and electrical channels of plasmon mediation impact the device PV performance with the eventual value being the subject of the trade-off between competing factors in complicated dependence of size, shape, component, and material parameters of metal nanostructures and absorber semiconductors. Microscopic calculations demonstrated that nonvertical interband transitions provide an effect unrelated to photoabsorption, nevertheless, which can promote the device efficiency by adjusting its internal electricity [23]. This electrical channel of the plasmon PV effect is ascribed to the decrease in the exciton binding energy, which assists the progress of exciton dissociation at the interface with the $\mathrm{TiO}_{2}$ porous electrode of a plasmonic PSC, resulting in the device PV performance enhancement.

\section{Conclusions}

We have investigated the synergistic effect of $\mathrm{Au}$ NRs and $\mathrm{MgO}$ on the PV performance of $\mathrm{CH}_{3} \mathrm{NH}_{3} \mathrm{PbI}_{3}$ based PSCs. By the simultaneous use of $\mathrm{Au} \mathrm{NRs}$ and $\mathrm{MgO}$, the power conversion efficiency of the PSC device increases from $14.7 \%$ to $17.4 \%$, displaying an over $18.3 \%$ enhancement, compared with the reference device without modification. It was found that the incorporated Au NRs increased the absorption cross-section and scattering cross-section of the incident light, and prominently promoted the near-field and the scattering efficiency chiefly by longitudinal plasmon resonances of gold NRs. Moreover, the presence of $\mathrm{MgO}$ significantly increases the $V_{\mathrm{OC}}$ of the device by reducing charge recombination. The aforementioned conclusions are revealed by $J-V$ curves, PL spectroscopy, EIS spectrum, and EQE analysis. As the advantage of $\mathrm{Au} \mathrm{NR}$ and $\mathrm{MgO}$ can be well-employed in this study, the photovoltaic performance of the PSC cells was significantly enhanced. The study suggests that the simultaneous use of $\mathrm{Au}$ NRs and $\mathrm{MgO}$ overlayer is an effective route in developing high-performance perovskite-based photoelectric devices.

Author Contributions: Conceptualization, S.H.; software, Z.W. (Zengbo Wang); investigation, C.Z., Z.X., Z.F., Z.W. (Zhixing Wu) and X.C.; writing—original draft preparation, Z.X.; writing—review and editing, S.H.; supervision, S.H. All authors have read and agreed to the published version of the manuscript.

Funding: This work was supported by Natural Science Foundation of Shanghai (Nos. 18ZR1411900, 18ZR1411000). The Large Instruments Open Foundation of East China Normal University and Foundation of Joint Institute of Advanced Science and Technology, East China Normal University, People's Republic of China.

Conflicts of Interest: The authors declare no conflict of interest.

\section{References}

1. Huang, J.; Yuan, Y.; Shao, Y.; Yan, Y. Understanding the physical properties of hybrid perovskites for photovoltaic applications. Nat. Rev. Mater. 2017, 2, 1-19. [CrossRef]

2. Green, M.A.; Ho-Baillie, A.; Snaith, H.J. The emergence of perovskite solar cells. Nat. Photonics 2014, 8, 506-514. [CrossRef]

3. Yang, L.; Wang, X.; Mai, X.; Wang, T.; Wang, C.; Li, X.; Murugadoss, V.; Shao, Q.; Angaiah, S.; Guo, Z. Constructing efficient mixed-ion perovskite solar cells based on $\mathrm{TiO}_{2}$ nanorod array. J. Colloid Interface Sci. 2019, 534, 459-468. [CrossRef] [PubMed]

4. Kojima, A.; Teshima, K.; Shirai, Y.; Miyasaka, T. Organometal halide perovskites as visible-light sensitizers for photovoltaic cells. J. Am. Chem. Soc. 2009, 131, 6050-6051. [CrossRef]

5. NREL Best Research-Cell Efficiency Chart. Available online: https://www.nrel.gov/pv/cell-efficiency.html (accessed on 10 August 2020).

6. Jeon, N.J.; Noh, J.H.; Kim, Y.C.; Yang, W.S.; Ryu, S.; Seok, S.I. Solvent engineering for high-performance inorganic-organic hybrid perovskite solar cells. Nat. Mater. 2014, 13, 897-903. [CrossRef]

7. Zhang, C.; Luo, Y.; Chen, X.; Chen, Y.; Sun, Z.; Huang, S. Effective improvement of the photovoltaic performance of carbon-based perovskite solar cells by additional solvents. Nano-Micro Lett. 2016, 8, 347-357. [CrossRef] 
8. Jiang, Q.; Zhao, Y.; Zhang, X.; Yang, X.; Chen, Y.; Chu, Z.; Ye, Q.; Li, X.; Yin, Z.; You, J. Surface passivation of perovskite film for efficient solar cells. Nat. Photonics 2019, 13, 460-466. [CrossRef]

9. Chi, W.; Banerjee, S.K. Progress in materials development for the rapid efficiency advancement of perovskite solar cells. Small 2020, 1907531. [CrossRef]

10. Kakavelakis, G.; Petridis, K.; Kymakis, E. Recent advances in plasmonic metal and rare-earth-element upconversion nanoparticle doped perovskite solar cells. J. Mater. Chem. A 2017, 5, 21604-21624. [CrossRef]

11. Moakhar, R.S.; Gholipour, S.; Masudy-Panah, S.; Seza, A.; Mehdikhani, A.; Riahi-Noori, N.; Tafazoli, S.; Timasi, N.; Lim, Y.F.; Saliba, M. Recent advances in plasmonic perovskite solar cells. Adv. Sci. 2020, 7, 1902448. [CrossRef]

12. Luo, Q.; Zhang, C.; Deng, X.; Zhu, H.; Li, Z.; Wang, Z.; Chen, X.; Huang, S. Plasmonic effects of metallic nanoparticles on enhancing performance of perovskite solar cells. ACS Appl. Mater. Interfaces 2017, 9, 34821-34832. [CrossRef]

13. Xu, Q.; Zhao, Y.; Zhang, X. Light management in monolithic perovskite/silicon tandem solar cells. Sol. $R R L$ 2020, 4, 1900206. [CrossRef]

14. Sun, S.; Salim, T.; Mathews, N.; Duchamp, M.; Boothroyd, C.; Xing, G.; Sum, T.C.; Lam, Y.M. The origin of high efficiency in low-temperature solution-processable bilayer organometal halide hybrid solar cells. Energy Environ. Sci. 2014, 7, 399-407. [CrossRef]

15. Wang, H.-P.; Lien, D.-H.; Tsai, M.-L.; Lin, C.-A.; Chang, H.-C.; Lai, K.-Y.; He, J.-H. Photon management in nanostructured solar cells. J. Mater. Chem. C 2014, 2, 3144-3171. [CrossRef]

16. Lee, J.H.; Park, J.H.; Kim, J.S.; Lee, D.Y.; Cho, K. High efficiency polymer solar cells with wet deposited plasmonic gold nanodots. Org. Electron. 2009, 10, 416-420. [CrossRef]

17. Ding, B.; Lee, B.J.; Yang, M.; Jung, H.S.; Lee, J.K. Surface-plasmon assisted energy conversion in dye-sensitized solar cells. Adv. Energy Mater. 2011, 1, 415-421. [CrossRef]

18. Wang, P.H.; Millard, M.; Brolo, A.G. Optimizing plasmonic silicon photovoltaics with Ag and Au nanoparticle mixtures. J. Phys. Chem. C. 2014, 118, 5889-5895. [CrossRef]

19. Chen, Y.; Li, Z.; Chen, X.; Liu, C.; Ye, X.; Wang, Z.; Sun, Z.; Huang, S. Improved performance of flexible amorphous silicon solar cells with silver nanowires. J. Appl. Phys. 2012, 112, 124320. [CrossRef]

20. Zhang, W.; Saliba, M.; Stranks, S.D.; Sun, Y.; Shi, X.; Wiesner, U.; Snaith, H.J. Enhancement of perovskite-based solar cells employing core-shell metal nanoparticles. Nano Lett. 2013, 13, 4505-4510. [CrossRef]

21. Saliba, M.; Zhang, W.; Burlakov, V.M.; Stranks, S.D.; Sun, Y.; Ball, J.M.; Johnston, M.B.; Goriely, A.; Wiesner, U.; Snaith, H.J. Plasmonic-induced photon recycling in metal halide perovskite solar cells. Adv. Funct. Mater. 2015, 25, 5038-5046. [CrossRef]

22. Yuan, Z.; Wu, Z.; Bai, S.; Xia, Z.; Xu, W.; Song, T.; Wu, H.; Xu, L.; Si, J.; Jin, Y. Hot-electron injection in a sandwiched $\mathrm{TiO}_{\mathrm{x}}-\mathrm{Au}-\mathrm{TiO}_{\mathrm{x}}$ structure for high-performance planar perovskite solar cells. Adv. Energy Mater. 2015, 5, 1500038. [CrossRef]

23. Jacak, W.A.; Jacak, J.E. New channel of plasmon photovoltaic effect in metalized perovskite solar cells. J. Phys. Chem. C. 2019, 123, 30633-30639. [CrossRef]

24. Laska, M.; Krzemińska, Z.; Kluczyk-Korch, K.; Schaadt, D.; Popko, E.; Jacak, W.; Jacak, J. Metallization of solar cells, exciton channel of plasmon photovoltaic effect in perovskite cells. Nano Energy 2020, 104751. [CrossRef]

25. Ball, J.M.; Stranks, S.D.; Hörantner, M.T.; Hüttner, S.; Zhang, W.; Crossland, E.J.; Ramirez, I.; Riede, M.; Johnston, M.B.; Friend, R.H. Optical properties and limiting photocurrent of thin-film perovskite solar cells. Energy Environ. Sci. 2015, 8, 602-609. [CrossRef]

26. Tan, H.; Jain, A.; Voznyy, O.; Lan, X.; De Arquer, F.P.G.; Fan, J.Z.; Quintero-Bermudez, R.; Yuan, M.; Zhang, B.; Zhao, Y. Efficient and stable solution-processed planar perovskite solar cells via contact passivation. Science 2017, 355, 722-726. [CrossRef]

27. Wang, Y.; Zhou, X.; Liang, C.; Li, P.; Hu, X.; Cai, Q.; Zhang, Y.; Li, F.; Li, M.; Song, Y. Enhanced efficiency of perovskite solar cells by using core-ultrathin shell structure $\mathrm{Ag} @ \mathrm{SiO}_{2}$ nanowires as plasmonic antennas. Adv. Electron. Mater. 2017, 3, 1700169. [CrossRef]

28. Gangadharan, D.T.; Xu, Z.; Liu, Y.; Izquierdo, R.; Ma, D. Recent advancements in plasmon-enhanced promising third-generation solar cells. Nanophotonics 2017, 6, 153-175. [CrossRef] 
29. Chan, K.; Wright, M.; Elumalai, N.; Uddin, A.; Pillai, S. Plasmonics in organic and perovskite solar cells: Optical and electrical effects. Adv. Opt. Mater. 2017, 5, 1600698. [CrossRef]

30. Nikoobakht, B.; El-Sayed, M.A. Preparation and growth mechanism of gold nanorods (NRs) using seed-mediated growth method. Chem. Mater. 2003, 15, 1957-1962. [CrossRef]

31. Jiang, Z.; Chen, X.; Lin, X.; Jia, X.; Zhuo, S. Amazing stable open-circuit voltage in perovskite solar cells using AgAl alloy electrode. Sol. Energy Mater. Sol. Cells 2016, 146, 35-43. [CrossRef]

32. Subramanian, V.; Wolf, E.E.; Kamat, P.V. Catalysis with $\mathrm{TiO}_{2} /$ gold nanocomposites. Effect of metal particle size on the Fermi level equilibration. J. Am. Chem. Soc. 2004, 126, 4943-4950. [CrossRef] [PubMed]

33. Zhang, C.; Luo, Q.; Shi, J.; Yue, L.; Wang, Z.; Chen, X.; Huang, S. Efficient perovskite solar cells by combination use of Au nanoparticles and insulating metal oxide. Nanoscale 2017, 9, 2852-2864. [CrossRef] [PubMed]

34. Domanski, K.; Correa-Baena, J.P.; Mine, N.; Nazeeruddin, M.K.; Abate, A.; Saliba, M.; Tress, W.; Hagfeldt, A.; Grätzel, M. Not all that glitters is gold: Metal-migration-induced degradation in perovskite solar cells. Acs Nano 2016, 10, 6306-6314. [CrossRef] [PubMed]

35. Wang, J.; Qin, M.; Tao, H.; Ke, W.; Chen, Z.; Wan, J.; Qin, P.; Xiong, L.; Lei, H.; Yu, H.; et al. Performance enhancement of perovskite solar cells with $\mathrm{Mg}$-doped $\mathrm{TiO}_{2}$ compact film as the hole-blocking layer. Appl. Phys. Lett. 2015, 106, 121104. [CrossRef]

36. Guo, X.; Dong, H.; Li, W.; Li, N.; Wang, L. Multifunctional MgO layer in perovskite solar cells. ChemPhysChem 2015, 16, 1727-1732. [CrossRef]

37. Dagar, J.; Castro-Hermosa, S.; Lucarelli, G.; Cacialli, F.; Brown, T.M. Highly efficient perovskite solar cells for light harvesting under indoor illumination via solution-processed $\mathrm{SnO}_{2} / \mathrm{MgO}$ composite electron transport layers. Nano Energy. 2018, 49, 290-299. [CrossRef]

38. Stratakis, E.; Kymakis, E. Nanoparticle-based plasmonic organic photovoltaic devices. Mater. Today 2013, 16, 133-146. [CrossRef]

39. Wang, D.H.; Kim, D.Y.; Choi, K.W.; Seo, J.H.; Im, S.H.; Park, J.H.; Park, O.O.; Heeger, A.J. Rücktitelbild: Enhancement of donor-acceptor polymer bulk heterojunction solar cell power conversion efficiencies by addition of Au nanoparticles. Angew. Chem. Int. Ed. 2011, 50, 5519-5523. [CrossRef]

40. Jang, Y.H.; Jang, Y.J.; Kim, S.; Quan, L.N.; Chung, K.; Kim, D.H. Plasmonic solar cells: From rational design to mechanism overview. Chem. Rev. 2016, 116, 14982-15034. [CrossRef]

41. Zhu, G.; Lin, T.; Lü, X.; Zhao, W.; Yang, C.; Wang, Z.; Yin, H.; Liu, Z.; Huang, F.; Lin, J. Black brookite titania with high solar absorption and excellent photocatalytic performance. J. Mater. Chem. A 2013, 1, 9650-9653. [CrossRef]

42. Boix, P.P.; Larramona, G.; Jacob, A.; Delatouche, B.; Mora-Seró, I.; Bisquert, J. Hole transport and recombination in all-solid $\mathrm{Sb}_{2} \mathrm{~S}_{3}$-sensitized $\mathrm{TiO}_{2}$ solar cells using $\mathrm{CuSCN}$ as hole transporter. J. Phys. Chem. C 2012, 116, 1579-1587. [CrossRef]

43. Barnes, P.R.; Anderson, A.Y.; Koops, S.E.; Durrant, J.R.; O’Regan, B.C. Electron injection efficiency and diffusion length in dye-sensitized solar cells derived from incident photon conversion efficiency measurements. J. Phys. Chem. C 2009, 113, 1126-1136. [CrossRef]

44. Morawiec, S.; Mendes, M.J.; Mirabella, S.; Simone, F.; Priolo, F.; Crupi, I. Self-assembled silver nanoparticles for plasmon-enhanced solar cell back reflectors: Correlation between structural and optical properties. Nanotechnology 2013, 24, 265601. [CrossRef] [PubMed]

45. Fan, W.; Yan, B.; Wang, Z.; Wu, L. Three-dimensional all-dielectric metamaterial solid immersion lens for subwavelength imaging at visible frequencies. Sci. Adv. 2016, 2, e1600901. [CrossRef]

46. Liu, L.; Zhong, H.; Bai, Z.; Zhang, T.; Fu, W.; Shi, L.; Xie, H.; Deng, L.; Zou, B. Controllable transformation from rhombohedral $\mathrm{Cu}_{1.8} \mathrm{~S}$ nanocrystals to hexagonal $\mathrm{CuS}$ clusters: Phase-and composition-dependent plasmonic properties. Chem. Mater. 2013, 25, 4828-4834. [CrossRef]

47. Johnson, P.B.; Christy, R.-W. Optical constants of the noble metals. Phys. Rev. B 1972, 6, 4370. [CrossRef]

48. Wintzheimer, S.; Granath, T.; Oppmann, M.; Kister, T.; Thai, T.; Kraus, T.; Vogel, N.; Mandel, K. Supraparticles: Functionality from uniform structural motifs. ACS Nano 2018, 12, 5093-5120. [CrossRef]

49. Li, J.; Cushing, S.K.; Meng, F.; Senty, T.R.; Bristow, A.D.; Wu, N. Plasmon-induced resonance energy transfer for solar energy conversion. Nat. Photonics 2015, 9, 601-607. [CrossRef] 
50. Sönnichsen, C.; Franzl, T.; Wilk, T.; Plessen, G.; Feldmann, J.; Wilson, O.; Mulvaney, P. Drastic reduction of plasmon damping in gold nanorods. Phys. Rev. Lett. 2002, 88, 077402.

51. Mackey, M.A.; Ali, M.R.; Austin, L.A.; Near, R.D.; El-Sayed, M.A. The most effective gold nanorod size for plasmonic photothermal therapy: Theory and in vitro experiments. J. Phys. Chem. B 2014, 118, 1319-1326. [CrossRef] 